\title{
CERN expels four Serbs to meet UN sanctions
}

Munich. CERN, the European Laboratory of Particle Physics, has been accused of breaking UN sanctions by allowing a small team of Serbian scientists to continue their research for a TESLA cyclotron being built in Belgrade. Following reports in the Swiss press last Sunday that criticized its conduct, CERN has told the four scientists that they must leave by the end of the month. The expulsion is the first in the 38-year history of the laboratory.

It is eight months since the United Nations imposed economic and cultural sanctions on Serbia, and it is not clear how the scientists managed to escape attention for so long. CERN says officially that it was hoped that the scientists would leave of their own accord and that they were given ample time to do so. But other interpretations suggest that the scientists were allowed to continue working because of a view that science and politics should be kept separate, and that they managed to avoid detection by keeping to themselves.

The former Yugoslavia was a founding member of CERN and, although leaving the organization in 1961, it has maintained a degree of scientific cooperation through its status as an 'observer'. But that relationship was believed to have ended this past summer, when Carlo Rubbia, CERN's director general, issued a written statement on 10 June that CERN would "fully comply" with the UN resolution prohibiting any type of interaction with Serbia. Since then, according to laboratory officials, CERN has taken "all the necessary measures to run down the activities of cooperation". Computer networks were shut down, the exchange of scientific materials was stopped and visits to Serbia by CERN personnel were prohibited. Nonetheless, the team of four scientists continued to work at CERN's laboratory in Geneva.

The national interdisciplinary laboratory at Vinča decided in the mid-1980s to develop the US $\$ 16$ million TESLA cyclotron as a research facility for local scientists and as a user facility and source of radioisotopes for medical purposes throughout the Balkans. In November 1990, CERN signed a collaborative agreement to provide advice on radiofrequency systems for TESLA, and eight scientists from Vinča were given cards allowing them access to CERN as unpaid visiting scientists. Four set up a laboratory to work on their model for the radiofrequency equipment, and since last summer they have had minimal contact with their home institute.

CERN no longer used cyclotrons, but officials arranged for a recently retired ex-

pert on cyclotron radiofrequency to continue working as an adviser to the group. This collaboration continues, supplemented as needed with impromptu advice from other CERN scientists.

Bosko Bojović, a Serbian research fellow who started work at CERN in January 1991, says that he and his colleagues are unhappy about being sent home before their model could be tested. Once they lose their CERN cards, he says, their visas will be rescinded and they will have to return to

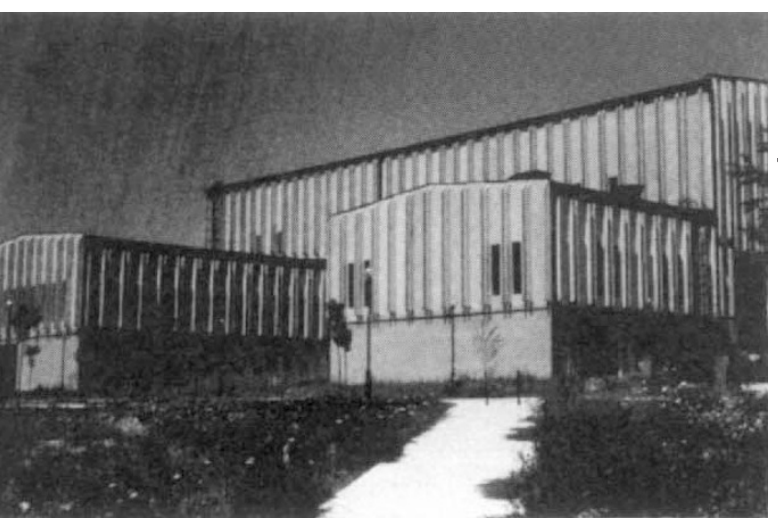

The laboratory has a long tradition of scientific exchanges. During the depths of the Cold War, scientists from the Soviet Union and eastern Europe were welcomed at CERN. Guy Hentsch of Rubbia's office says that CERN "wanted to act in a decent way and give them time to leave spontaneously". It was regrettable, he says, that they eventually had to be told they were no longer welcome.

But CERN's role in the incident is unclear. A report in Switzerland's populist newspaper La Suisse, which wrongly suggested that the cyclotron could be used for military purposes, portrayed Hentsch as being sympathetic to the plight of the group by quoting him as saying that it would be cruel "to break up a phase of their project just before it was finished". The Serbian scientists say they were given neither an official nor an unofficial directive about leaving CERN and were always made to feel welcome, at least by their immediate colleagues. The Vinča Institute says that it had understood that their colleagues would not actually be thrown out unless Serbia increased its role in the war.

Belgrade. "We will certainly not be able to carry on our work at home," he adds.

The Serbian scientists say that they were allowed to continue their work because the TESLA cyclotron is intended to be used primarily for medical research and was therefore exempt from sanctions. CERN officials deny this and say that the work should have been stopped much earlier.

\section{Monthly Nature's launch in Moscow}

London. A trial edition of a monthly issue of Nature will be produced in Moscow next Monday and distributed to some hundreds of people at a reception at the People's House of Science as well as more generally. The trial issue will contain contributions appearing in Nature in three issues towards the end of 1992. The intention is that this first issue will be followed, no later than April, by the regular publication of a selection of contributions from the previous month's issues of the standard edition of Nature.

The new periodical, called Monthly $\mathrm{Na}$ ture, will be in English to avoid the costs and delays of translation. The selection of each month's contents will be made in Moscow by a committee of Russian scientists. It is intended that the new journal will circulate not only in Russia but also in the other republics of the Commonwealth of Independent States.

The production of the trial edition has
Once the Serbian group returns home, any hope of building the cyclotron, whose housing complex in Belgrade is already complete, depends upon the sanctions being lifted. Back in Geneva, CERN will need to find a more convincing way of answering charges that it ignored UN sanctions if it wants to lay to rest an unpleasant incident.

Alison Abbott been arranged by Yury Eldyshev and Carl Levitin, previously joint managing editors of the Academy of Sciences journal Priroda (which means 'nature'), who will also be employed by a Nature enterprise being established in Moscow to manage the regular monthly production. The new arrangement will not disturb the long-standing collaboration between Nature and Priroda.

The immediate objective of Monthly Nature is to make the essence of each month's Nature accessible to and affordable by scientists in the republics of the Commonwealth of Independent States. The management of Nature sees this as an interim goal on the way to the publication of the regular weekly edition somewhere in the territory where the ruble is the standard currency. The standard weekly edition of Nature is already produced once a week in Virginia (United States), Tokyo (Japan) and Beijing (China) as well as in Britain. 